\title{
A Life Course Approach to Hearing Health
}

\author{
Shirley A. Russ, Kelly Tremblay, Neal Halfon, \\ and Adrian Davis
}

\section{Introduction}

Challenges to hearing health are a significant public health problem.

At least ten million Americans have a hearing loss that interferes with the understanding of normal speech (Mitchell 2005). If lesser degrees of loss are included, the number rises to 28 million (US DHHS 2010). Sensorineural hearing loss

S.A. Russ, MD, MPH $(\bowtie)$

UCLA Center for Healthier Children, Families and Communities, Department of Pediatrics, David Geffen School of Medicine, UCLA,

Los Angeles, CA, USA

e-mail: shirlyruss@cox.net

K. Tremblay

Speech \& Hearing Sciences College of Arts \&

Sciences, University of Washington,

Seattle, WA, USA

\section{N. Halfon}

Department of Pediatrics, David Geffen School of Medicine, UCLA, Los Angeles, CA, USA

Department of Health Policy and Management, Fielding School of Public Health, UCLA, Los Angeles, CA, USA

Department of Public Policy, Luskin School of Public Affairs, UCLA, Los Angeles, CA, USA

Center for Healthier Children, Families, and Communities, UCLA, Los Angeles, CA, USA

A. Davis

University College London, NHS Newborn Hearing

Screening Program, London, UK
(SNHL) is the commonest sensory deficit in more developed societies (Davis 1989). The term "deaf" is usually reserved for individuals with severe (>60-90 dBHL) or profound ( $>90 \mathrm{dBHL}$ ) losses, representing half a million Americans, while those with mild ( $<40 \mathrm{dBHL})$ or moderate (40-60 dBHL) losses are referred to as "hard of hearing" (Smith et al. 2005; Blanchfield et al. 2001). Congenital losses sufficient to adversely affect speech and language development are seen in at least one per thousand newborns (Fortnum et al. 2001; Russ et al. 2003; Van Naarden et al. 1999), and if lesser degrees of loss and unilateral losses are included, this number rises to up to five per thousand. Only $4 \%$ cases of hearing loss nationwide are accounted for by children under the age of 18 years, while $50 \%$ cases occur in persons 65 years of age or older (Russ 2001). The cumulative prevalence of hearing loss within the US population rises with age, as has been demonstrated in other countries (Russ 2001; Parving and Christensen 1996), with the sharpest rise in prevalence occurring in old age, when $50-80 \%$ are ultimately affected (see Table 1 ). The relative contributions of delayed diagnosis of congenital losses, progression of existing losses, and acquisition of new losses to the rising prevalence of hearing loss with age are uncertain. Improvements to the prevention, diagnosis, and management of hearing loss across all age groups are public health priorities (Reavis et al. 2016; Davis et al. 2016). 
Table 1 Prevalence of hearing loss in the USA across the life span

\begin{tabular}{|c|c|c|c|c|c|}
\hline Age & $\begin{array}{l}\text { Estimated } \\
\text { prevalence of } \\
\text { hearing loss } \\
\%(95 \% \mathrm{CI})\end{array}$ & Case definition & $\begin{array}{l}\text { Author and year of } \\
\text { study }\end{array}$ & $\begin{array}{l}\text { Place of study and } \\
\text { sample size }\end{array}$ & Data source \\
\hline Newborn & $0.14 \%$ & $\begin{array}{l}\text { Bilateral loss }>35 \\
\text { dBHL requiring } \\
\text { amplification }\end{array}$ & $\begin{array}{l}\text { Mason, Herrman } \\
\text { 1992-1997 }\end{array}$ & $\begin{array}{l}\text { Honolulu, HI, } \\
10,372\end{array}$ & $\begin{array}{l}\text { Kaiser Permanente } \\
\text { Honolulu, HI, NHSP }\end{array}$ \\
\hline Newborn & $0.19 \%$ & $\begin{array}{l}\text { Loss } \geq 35 \mathrm{dBHL} \text { in } \\
\text { one or both ears }\end{array}$ & $\begin{array}{l}\text { Mehl, Thompson } \\
\text { 1992-1999 }\end{array}$ & $\begin{array}{l}\text { Colorado } \\
63,590\end{array}$ & Colorado NHSP \\
\hline Newborn & $0.31 \%$ & $\begin{array}{l}\text { Unilateral and } \\
\text { bilateral } \\
\text { sensorineural and } \\
\text { conductive losses }\end{array}$ & $\begin{array}{l}\text { Finitzo, Albright, } \\
\text { O’Neal } \\
\text { 1994-1997 }\end{array}$ & $\begin{array}{l}\text { Texas } \\
54,228\end{array}$ & $\begin{array}{l}\text { Texas Newborn } \\
\text { Hearing Screening } \\
\text { Data }\end{array}$ \\
\hline Newborn & $0.33 \%$ & $\begin{array}{l}\text { Unilateral and } \\
\text { bilateral } \\
\text { sensorineural } \\
\text { hearing loss }\end{array}$ & $\begin{array}{l}\text { Barsky-Firsker, Sun } \\
\text { 1993-1995 }\end{array}$ & $\begin{array}{l}\text { Livingston, New } \\
\text { Jersey, 15,749 }\end{array}$ & $\begin{array}{l}\text { St. Barnabas Medical } \\
\text { Center Newborn } \\
\text { Hearing Screening } \\
\text { Data }\end{array}$ \\
\hline 3 years & $\begin{array}{l}0.067 \% \\
(0.053- \\
0.085)\end{array}$ & \multirow{2}{*}{$\begin{array}{l}\text { Bilateral PTA loss } \\
\text { at } 0.5,1 \text {, and } 2 \\
\mathrm{KHz} \geq 40 \mathrm{dBHL} \text { in } \\
\text { better unaided ear }\end{array}$} & \multirow[t]{2}{*}{$\begin{array}{l}\text { Van Naarden, } \\
\text { Decoufle, Caldwell } \\
\text { 1991-1993 }\end{array}$} & \multirow[t]{2}{*}{$\begin{array}{l}\text { Metropolitan } \\
\text { Atlanta 255,742 }\end{array}$} & \multirow{2}{*}{$\begin{array}{l}\text { Metropolitan Atlanta } \\
\text { Developmental } \\
\text { Disabilities } \\
\text { Surveillance Program } \\
\text { (MADDSP) }\end{array}$} \\
\hline 10 years & $\begin{array}{l}0.14 \% \\
(0.12-0.16)\end{array}$ & & & & \\
\hline 8 years & $\begin{array}{l}0.14 \% \\
0.12 \%\end{array}$ & $\begin{array}{l}\text { Bilateral PTA loss } \\
\text { at } 0.5,1 \text {, and } 2 \\
\mathrm{KHz} \geq 40 \mathrm{dBHL} \text { in } \\
\text { better unaided ear }\end{array}$ & $\begin{array}{l}\text { Karapurkar Bhasin, } \\
\text { Brocksen, Avchen, } \\
\text { Van Naarden Braun } \\
1996 \text { and } 2000\end{array}$ & $\begin{array}{l}\text { Metropolitan } \\
\text { Atlanta } \\
36,749(1996) \\
43,593(2000) \\
\end{array}$ & MADDSP \\
\hline \multirow[t]{3}{*}{ 6-19 years } & $0.4 \%$ & $\begin{array}{l}\text { Bilateral loss at } \\
\text { low }(0.5,1 \text {, and } 2 \\
\text { kHZ) frequencies } \\
\text { PTA } \geq 26 \mathrm{dBHL}\end{array}$ & \multirow[t]{3}{*}{$\begin{array}{l}\text { Niskar, Kieszak, } \\
\text { Holmes, et al. } \\
\text { 1988-1994 }\end{array}$} & \multirow[t]{3}{*}{ USA 5249} & \multirow[t]{3}{*}{ NHANES III } \\
\hline & $0.7 \%$ & $\begin{array}{l}\text { Bilateral loss at } \\
\text { high }(3,4 \text {, and } 6 \\
\text { kHZ) frequencies } \\
\text { PTA } \geq 26 \mathrm{dBHL}\end{array}$ & & & \\
\hline & $14.9 \%$ & $\begin{array}{l}\text { Unilateral or } \\
\text { bilateral loss PTA } \\
>16 \mathrm{dBHL} \text { at low } \\
\text { or high frequencies }\end{array}$ & & & \\
\hline $18-34$ years & $3.4 \%$ & $\begin{array}{l}\text { Self-reported } \\
\text { hearing trouble }\end{array}$ & $\begin{array}{l}\text { National Center for } \\
\text { Health Statistics } \\
(1990 \text { and 1991) }\end{array}$ & USA 239,663 & $\begin{array}{l}\text { National Health } \\
\text { Interview Survey } \\
\text { (NHIS) }\end{array}$ \\
\hline $35-44$ years & $6.3 \%$ & $\begin{array}{l}\text { Self-reported } \\
\text { hearing trouble }\end{array}$ & $\begin{array}{l}\text { National Center for } \\
\text { Health Statistics } \\
\text { (1990 and 1991) }\end{array}$ & USA 239,663 & $\begin{array}{l}\text { National Health } \\
\text { Interview Survey } \\
\text { (NHIS) }\end{array}$ \\
\hline $45-54$ years & $10.3 \%$ & $\begin{array}{l}\text { Self-reported } \\
\text { hearing trouble }\end{array}$ & $\begin{array}{l}\text { National Center for } \\
\text { Health Statistics } \\
\text { (1990 and 1991) }\end{array}$ & USA 239,663 & $\begin{array}{l}\text { National Health } \\
\text { Interview Survey } \\
\text { (NHIS) }\end{array}$ \\
\hline $48-59$ years & $21 \%$ & \multirow{3}{*}{$\begin{array}{l}\text { PTA } 0.5,1,2 \text {, and } \\
4 \mathrm{KHz}>25 \mathrm{dBHL} \\
\text { in the worst ear }\end{array}$} & \multirow{3}{*}{$\begin{array}{l}\text { Cruickshanks, } \\
\text { Wiley, Tweed, et al. }\end{array}$} & \multirow{3}{*}{$\begin{array}{l}\text { Beaver Dam, WI, } \\
\text { (EHLS) } 4541\end{array}$} & \multirow{3}{*}{$\begin{array}{l}\text { Epidemiology of } \\
\text { Hearing Loss Study } \\
\text { (EHLS) }\end{array}$} \\
\hline $70-79$ years & $66 \%$ & & & & \\
\hline 80 years & $90 \%$ & & & & \\
\hline
\end{tabular}


Table 1 (continued)

\begin{tabular}{l|l|l|l|l|l}
\hline & $\begin{array}{l}\text { Estimated } \\
\text { prevalence of } \\
\text { hearing loss } \\
\%(95 \% \mathrm{CI})\end{array}$ & Case definition & $\begin{array}{l}\text { Author and year of } \\
\text { study }\end{array}$ & $\begin{array}{l}\text { Place of study and } \\
\text { sample size }\end{array}$ & Data source \\
\hline 60-90 years & $29 \%$ & $\begin{array}{l}\text { PTA 0.5, 1, and 2 } \\
\text { KHz }>26 \text { dBHL in } \\
\text { the better ear }\end{array}$ & $\begin{array}{l}\text { Gates, Cooper, } \\
\text { Kannel, et al. } \\
\text { 1983-1985 }\end{array}$ & Framingham 1662 & $\begin{array}{l}\text { Framingham Heart } \\
\text { Study }\end{array}$ \\
\hline $73-84$ years & $59.9 \%$ & $\begin{array}{l}\text { Hearing loss: two } \\
\text { averages of } \\
\text { thresholds 0.5, 1, } \\
\text { and 2 KHz }>25 \\
\text { dBHL }\end{array}$ & $\begin{array}{l}\text { Helzner, Cauley, } \\
\text { Pratt, et al. } \\
\text { 1997-1998 }\end{array}$ & $\begin{array}{l}\text { Pittsburgh, } \\
\text { Pennsylvania, and } \\
\text { Memphis, } \\
\text { Tennessee, 2052 }\end{array}$ & $\begin{array}{l}\text { Health, Aging, and } \\
\text { (ABC) Study }\end{array}$ \\
\cline { 2 - 3 } & $76.9 \%$ & $\begin{array}{l}\text { High-frequency } \\
\text { hearing loss }>40 \\
\text { dBHL 2, 4, and } 8 \\
\text { KHz }\end{array}$ & & & \\
\hline
\end{tabular}

Although there have been considerable advances in understanding the etiology of hearing loss, with genetic causes now thought to account for up to $50 \%$ of congenital losses (Mitchell 2005), in many individual cases, the cause of hearing loss remains unknown. Even where genetic causes have been identified, discovery of the abnormal gene does not necessarily lead to an understanding of the mechanism whereby the gene's product exerts its effect. Similarly, genetic and environmental causes of hearing losses that have their onset later in life have not been well defined. This lack of knowledge of the basic pathophysiology of hearing difficulties hampers prevention and treatment efforts.

Hearing health has important implications for general health and well-being. Both children and adults with hearing loss face significant educational and social challenges. For children who are profoundly deaf, language and academic levels at high school graduation have been reported historically to correspond to those of fourth grade students with normal hearing (Holt 1993). Adults with hearing loss are reported to have higher levels of unemployment (Parving and Christensen 1993) and lower quality of life than their hearing peers (Appollonio et al. 1996). For older individuals, hearing disability is associated with accelerated cognitive decline, depression, increased risk of dementia, poorer balance, falls, hospitaliza- tions, and early mortality (for a review, see Davis et al. 2016). In addition to these medical consequences, there are also social functioning implications including social isolation due to reduced communication, loss of autonomy, and financial decline. Traditionally, hearing losses in childhood and in adult life have been considered as separate issues.

Growing interest in life course theory has led to suggestions that it could prove useful to apply a life course lens to the study of hearing loss, and of hearing health, throughout the life span. The early years of life, especially the period from conception through to 3 years of age, are now understood to impact lifelong health. Childhood conditions and early experiences can become "embedded" into emerging biological systems, altering health trajectories. The Life Course Health Development (LCHD) model posits that health is an emergent capacity of human beings that dynamically develops over time in response to multiple-nested, ever-changing genetic, biological, behavioral, social, and economic contexts. Multiple risk and protective factors influence development of key biological systems, including the anatomic and biochemical determinants of hearing ability, during critical and sensitive periods of development (see Table 2). Health, at individual and population levels, is also influenced by the timing and sequence of biological, 
Table 2 Risk and protective factors for hearing loss across the life span

\begin{tabular}{|c|c|c|}
\hline Life stage & Risk factor & Protective factor \\
\hline Prenatal & $\begin{array}{l}\text { 1. Syndrome association with HL } \\
\text { 2. Family history of permanent } \\
\text { childhood SNHL } \\
\text { 3. Craniofacial anomalies } \\
\text { 4. In utero TORCH }\end{array}$ & 1. Maternal rubella immunization \\
\hline Perinatal & $\begin{array}{l}\text { 1. NICU }>48 \mathrm{~h} \\
\text { 2. Jaundice-exchange Tx } \\
\text { 3. Ototoxic medications } \\
\text { 4. Meningitis }\end{array}$ & $\begin{array}{l}\text { 1. Prompt treatment for neonatal } \\
\text { jaundice. } \\
\text { 2. Avoid/monitor ototoxic medications. } \\
\text { 3. Prompt antibiotic treatment for } \\
\text { meningitis }\end{array}$ \\
\hline Early childhood & $\begin{array}{l}\text { Pre- and Perinatal risk factors, plus: } \\
\text { 1. Parent/caregiver concern } \\
\text { 2. Persistent pulmonary hypertension } \\
\text { with ventilation. } \\
\text { 3. Conditions requiring ECMO } \\
\text { 4. Syndromes associated with } \\
\text { progressive hearing loss (e.g., } \\
\text { neurofibromatosis, osteopetrosis, } \\
\text { Usher's) } \\
\text { 5. Neurodegenerative disorder (e.g., } \\
\text { Hunter's, sensorimotor neuropathies, } \\
\text { Friedreich's ataxia, } \\
\text { Charcot-Marie-Tooth) } \\
\text { 6. Head trauma } \\
\text { 7. Recurrent/persistent OME for } \geq 3 \\
\text { months }\end{array}$ & $\begin{array}{l}\text { 1. Immunization } \\
\text { 2. Avoid/monitor ototoxic medications. } \\
\text { 3. Prompt antibiotic treatment for } \\
\text { meningitis } \\
\text { 4.Head injury prevention } \\
\text { 5.Noise avoidance/protection }\end{array}$ \\
\hline $\begin{array}{l}\text { Middle childhood, } \\
\text { adolescence, and adulthood }\end{array}$ & $\begin{array}{l}\text { Early childhood risk factors plus: } \\
\text { Noise } \\
\text { Drug/chemical exposure } \\
\text { Head trauma } \\
\text { Otosclerosis }\end{array}$ & $\begin{array}{l}\text { 1. Noise avoidance/protection } \\
\text { 2. Avoid/monitor ototoxic drugs } \\
\text { 3. Head injury prevention } \\
\text { 4. Immunizations } \\
\text { 5. Higher family income } \\
\text { 6. Education }\end{array}$ \\
\hline
\end{tabular}

cultural, and historic events and experiences. Application of the LCHD model to hearing health challenges predominantly biomedical models and suggests that there are multiple potential avenues for improving hearing health. As hearing losses in childhood and in adult life have been considered as separate issues, investigations into adult hearing loss largely ignore early-life exposures. However, the LCHD model highlights the importance of studying these links.

In this paper we consider the implications of the LCHD model for understanding the mechanisms, pathways, and determinants of hearing ability. We consider the implications of early hearing loss for health development over the life course and the factors through the life course that contribute to hearing ability in adult life. We consider the concept not just of hearing loss but of "hearing health" and how to achieve it, the research priorities that are suggested by this review, and the implications for policy and practice.

\section{The Life Course Health Development Model and the Mechanisms, Pathways, and Determinants of Hearing Ability}

According to Halfon and Forrest (2017), the LCHD model is grounded in the following seven principles:

1. Health development: Health development integrates the concepts of health and developmental processes into a unified whole. 
2. Unfolding: Health development unfolds continuously over the life span, from conception to death, and is shaped by prior experiences and environmental interactions.

3. Complexity: Health development results from adaptive, multilevel, and reciprocal interactions between individuals and their physical, natural, and social environments.

4. Timing: Health development is sensitive to the timing and social structuring of environmental exposures and experiences.

5. Plasticity: Health development phenotypes are malleable and enabled and constrained by evolution to enhance adaptability to diverse environments.

6. Thriving: Optimal health development promotes survival, enhances well-being, and protects against disease.

7. Harmony: Health development results from the balanced interactions of molecular, physiological, behavioral, cultural, and evolutionary processes.

Taken together, these seven principles suggest that in order to understand the mechanisms underlying hearing loss and hearing health from a life course standpoint, it is essential to explore the role of multiple risk and protective factors operating at multiple levels to influence hearingrelated outcomes. In addition, scientists must study the emergence and development of hearing health trajectories over extended time frames, including the pivotal role of social relationships in the development of functional hearing capacity. Researchers must consider the critical importance of timing in relation to sensitive periods and turning points in the development of hearing abilities. All of these principles point to the importance of adopting a developmental perspective on hearing health. The following section takes each of these issues in turn, providing a review of the evidence pertaining to each.

\subsection{Multiple Risk and Protective Factors}

Traditional approaches to investigation of the etiology of hearing loss have focused on finding a single or principal cause for clinically observed losses; however, etiology of hearing loss remains unknown in $35-55 \%$ most reported case series (Das 1996).

\subsubsection{Genetics}

Over the past two decades, there has been an explosion in understanding of the genetic basis of deafness. Over half of newborns with SNHL are now believed to have a genetic cause for their loss. Over 120 independent genes for deafness have been identified (Nance 2003). More than 40 are associated with nonsyndromic dominant deafness and more than 30 with autosomal recessive nonsyndromic deafness (Bitner-Glindzicz 2002). Most newborns with inherited forms of hearing loss are born to hearing parents and have recessive, nonsyndromic losses (Russ et al. 2003). Mutations in a single gene-GJB2, coding for the connexin 26 protein which contributes to gap junctions in inner ear cells-are now believed to account for almost half of cases of hereditary nonsyndromic SNHL in America (Davis et al. 1990; Kelley et al. 2000; Cohn and Kelley 1999), with autosomal dominant, X-linked and mitochondrial mutations accounting for the remainder (Russ et al. 2003). Frequently, hearing loss occurs alongside associated conditions. The commonest form of syndromic SNHL is Pendred syndrome, where hearing loss is associated with thyroid abnormalities. Other syndromic losses include Usher's syndrome, Waardenburg syndrome, Alport syndrome, and branchio-oto-renal syndrome. Not all genetic losses are expressed at birth. For example, although the mutation in the pendrin gene is present at birth, Pendred syndrome may be missed in the neonatal period as initial loss may be mild and progress over time, while the thyroid abnormality may not present at birth (Russ et al. 2003). In Usher's syndrome, hearing loss may precede accompanying vision loss by several years.

\subsubsection{Gene-Environment Interactions and Epigenetics}

It is becoming increasingly clear that even welldescribed single-gene mutations known to result in hearing loss have a variety of expressed phenotypes. Clinical phenotypes may vary depending 
on either the effects of modifier genes or on geneenvironment interactions. Functional modifications to the genome, referred to as "epigenetics," may result from DNA methylation, histone protein modification, and other mechanisms, and may occur only under certain environmental conditions. For some individuals, a genetic predisposition to hearing loss may only result in phenotypic expression under certain environmental circumstances, and in others, hearing loss may only be manifest in late childhood, adolescence, or adult life.

One of the best-described gene-environment mechanisms leading to expression of hearing loss is that involving the mitochondrial mutation, A1555G, where hearing loss in some individuals occurs only after exposure to aminoglycosides (Gurtler et al. 2005; Fischel-Ghodsian 2003). Epigenetic modifications may result in either temporary or permanent upregulation or downregulation of transcription of certain genes. The timing and duration of key environmental triggers may greatly influence the clinical phenotype. It is not yet known whether there are times in the life span beyond the prenatal period and the first years of life, such as puberty and menopause which are particularly sensitive to environmental effects.

\subsubsection{Environmental Causes of Hearing Loss}

Environmental causes of congenital hearing loss include congenital TORCH infections (toxoplasmosis, rubella, cytomegalovirus and herpes), prematurity, birth asphyxia, jaundice, and ototoxic drugs. Although prematurity and low birthweight are known to be associated with congenital hearing loss, the causal pathway has not been clearly delineated. One study in Atlanta showed elevated relative risks of bilateral sensorineural hearing impairment among children with lower birthweights: prevalence was $0.4 / 1000$ in children weighing $\geq 4000 \mathrm{~g}$, compared with $1.27 / 1000$ for 1500-1499 $\mathrm{g}$ and 5.1/1000 for those $<1500 \mathrm{~g}$ (Van Naarden and Decoufle 1999). Admission to a Neonatal Intensive Care Unit (NICU) is a known risk factor for hearing loss, with prolonged mechanical ventilation, birth asphyxia, jaundice, extracorporeal membrane oxygenation (ECMO), and ototoxic medications all contributing risk. While a principal cause for hearing loss might be identifiable in individual cases, infants at this sensitive stage of aural development might be particularly susceptible to the cumulative effects of multiple risks on the infant's hearing ability and to interactions between risk factors (Fligor et al. 2005, Marlow et al. 2000). For infants who have undergone ECMO, hearing loss may not be detected immediately but appears later in infancy or childhood, implying that the effects of the environmental agent in some way continue even after the period of exposure. Similarly, the influence of these early risk factors for hearing loss may not operate solely during childhood, but may continue throughout the life course. One recent study has shown a higher risk of SNHL in males aged 18 who were born small for gestational age (Barrenas et al. 2005b) and in males of short stature (Barrenas et al. 2005a). This interesting finding has led to the hypothesis that fetal programming arising from intrauterine growth retardation might result in delayed cell cycles during development of the cochlea which eventually leads to development of SNHL in adulthood (Niskar et al. 2001). If this is the case, then some newborns who have normal hearing thresholds at birth may have underlying auditory system compromise which only becomes clinically apparent in later life.

Hearing ability in the newborn period, then, may be best conceptualized as a spectrum, with the subsequent hearing trajectory followed by each child depending both on baseline hearing capacity together with the effects of multiple hearing risk and protective factors operating through the life course (see Fig. 1).

Prolonged otitis media in childhood is known to be associated with transient conductive hearing loss; however, its role in the pathogenesis of permanent hearing loss is uncertain. In one series, self-reported hearing loss was recorded in $30 \%$ of young patients who had had secretory otitis media for more than 6 years (Ryding et al. 2005), while in another study only boys who had been treated with tympanostomy tubes were at increased risk of loss $>20 \mathrm{dBHL}$ for at least one 


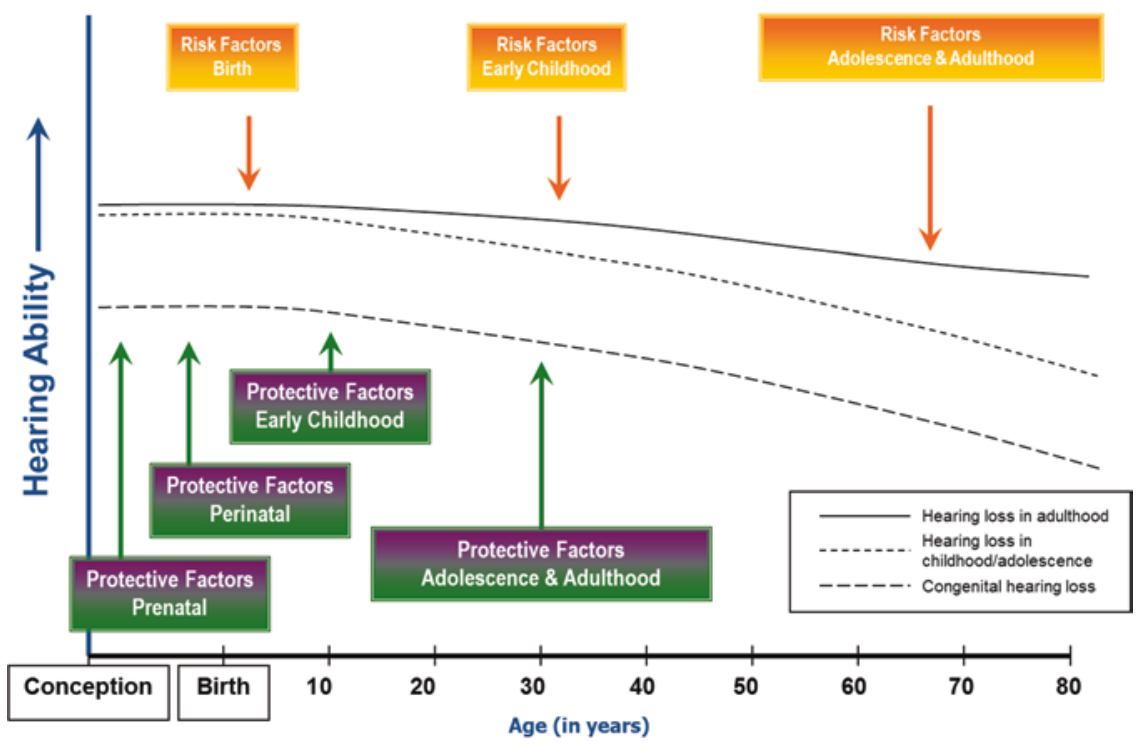

Fig. 1 Hearing loss trajectories

frequency at the age of 18 years (Augustsson and Engstrand 2005).

The environmental risk factor most closely studied for hearing loss in adulthood is noise exposure. Over 11 million Americans have regular exposure to sound levels which have the potential to damage hearing (National Institute in Deafness and Other Communication Disorders 2002), and many of these exposures are related to occupations, e.g., mining, farm work, entertainment industry, or recreational activities, e.g., rock concerts or motorcycles. While noise-induced hearing loss is typically gradual and insidious, starting with a notched loss in the high frequencies, sudden hearing loss has also been reported in response to acoustic trauma, e.g., gunshot or explosion (Danielson 2005). With that said, noise exposure can manifest itself even without the presence of an observed audiometric impact, making the prevalence much greater than originally thought. For example, Tremblay et al. (2015) reported a history of noise exposure, to be a primary risk factor among adults' self-reporting hearing difficulties, even when there was no audiometric evidence of hearing loss.

Interactions between noise exposure and other risk factors for hearing loss, such as those present from infancy and childhood, have not been well studied, though smoking has been shown to increase risk of high-frequency loss and to exert an additive risk effect with noise exposure (Uchida et al. 2005). Evidence is emerging that exposure to leisure-time noise in young adults results in detectable changes to hearing capacity, indicated by decreased transient evoked otoacoustic emission (TEOAE) levels and reproducibility even when hearing thresholds remain normal ( $>20$ dBHL) (Rosanowski et al. 2006). Noise-induced threshold shifts have been observed in up to $12.5 \%$ children ages 6-19 years (Niskar et al. 2001). Of young people who responded to a recent web-based survey, $61 \%$ reported experiencing tinnitus or hearing loss following attendance at loud music concerts (Chung et al. 2005). Compliance with recommendations regarding use of ear protection for those at risk of occupational exposure or for leisure-related exposures is generally low.

Despite the high prevalence of presbycusis, or age-related hearing loss, in the USA, the mechanism of pathogenesis has not been fully elucidated and appears to be multifactorial (Gates and Mills 2005), involving genetic and environmental influences. A Danish study of twins aged 
75 and older estimated a heritability factor of $40 \%$ for self-reported reduced hearing (Christensen et al. 2001) and suggested that even older adults with hearing loss should be asked about familial risk factors. Interestingly, in a genome-wide linkage analysis in the Framingham Heart Study, several of the chromosome locations linked to presbycusis overlapped with loci known to cause congenital hearing loss, raising the possibility that the same genes might cause presbycusis and congenital hearing loss (DeStefano et al. 2003). In individual cases, it can be challenging to distinguish age-related and noise-induced hearing loss, and in some cases both factors may contribute to the clinical picture. Adults, too, remain at risk of hearing loss secondary to bacterial meningitis, head injuries, and exposure to ototoxic medications.

While multiple risk and protective factors contribute to defined hearing deficits and elevated hearing thresholds, additional factors operating at multiple levels influence functional outcomes for individuals with hearing loss. It is well recognized that two individuals with the same hearing loss etiologies may have identical audiometric thresholds, yet one is apparently asymptomatic while the other reports significant difficulties with hearing. Contributing factors may include different hearing environments-one individual may work or attend school in a less optimal acoustic environment than the other-or subtle differences in hearing pathology affecting, e.g., speech discrimination. Differences in speech understanding, among individuals with similar audiograms, also appear along the aging trajectory. Individuals with similar chronological ages show differences in the ability to conduct sound along central auditory pathways (Clinard and Tremblay 2013). For children with congenital hearing loss, functional communication outcomes are sensitive to age at diagnosis of hearing loss, age at onset of intervention, socioeconomic status, and degree of family engagement.

\subsection{Hearing Health Trajectories}

Baltes, Lindenberger, and Staudinger (2007) describe four distinct phases of health development:
- Phase 1-Generativity: Preconception and prenatal period is dedicated to the formation of the organism, within the context in which the developing fetus will emerge. This phase can include the nutritional inputs and neuralhormonal contexts that influence the mother's reproductive health trajectory, including early influences on the eggs that are developing in her ovaries years before she is reproductively able.

- Phase 2-Acquisition of capacity: The early years are dedicated to the development, acquisition, and optimization of specific capacities, including investing in future health potential and anticipated developmental reserves.

- Phase 3 - Maintenance of function: The middle years are dedicated to maintaining function of these capacities in the face of accumulating risks and ongoing weathering.

- Phase 4 - Managing decline: The later years are dedicated to managing, adjusting, and adapting to functional decline of various body and regulatory systems.

These Phases are readily applicable to the study of the development of hearing health.

\subsubsection{Generativity}

Outside of genetic factors, there have been few studies addressing women's preconception health and future risk of hearing loss in any children she might conceive. There has been little research into maternal preconception nutritional factors or neurohormonal variants that might pose a risk for future fetal auditory system development and function. The prenatal period has been more intensively studied, and multiple genetic and environmental factors contributing to disruption of hearing ability have been described. However, too often, underlying pathophysiologic mechanisms have not been fully delineated. Formation of the auditory system in the fetus is a complex process, apparently sensitive to the effects of multiple gene products and environmental variants. In addition, hearing loss frequently occurs alongside other developmental effects either as part of a defined syndrome or for reasons that are obscure. Abnormalities can arise in the absence of a gene product, the formation of an abnormal 
gene product, and/or in the regulation of a gene's expression. Pathology can occur at the molecular, subcellular, cellular, or organ formation stages. Environmental effects may operate via disruption to the normal process of genetic transcription and translation or through mechanisms that are independent of the genome, e.g., direct disruption of developing tissues. Environmental factors may act through more than one mechanism, and clinical effects may vary significantly based on timing of exposure in relation to gestation. Effects on different organs of a single genetic or environmental factor may be similar or quite different. Consequently, elucidation of the pathophysiology of hearing loss requires a cooperative effort across multiple disciplines and approaches.

\subsubsection{Acquisition of Capacity}

Study of hearing ability during the early years has largely been limited to measurement of auditory thresholds, yet children with identical thresholds may have very different hearing reserves, hearing potential, and hearing function. There is moderately good evidence that auditory input in the first 6 months of life is important for the development of functional hearing ability, suggesting that in some way the stimulation of auditory neurons in early postnatal life is necessary for the acquisition of full hearing capacity (Levine et al. 2016). Among children with congenital hearing loss, adaptations such as the early use of hearing aids or acquisition of lip-reading skills may affect either physiologic hearing ability or functional hearing through stimulation of higher auditory pathways. Similarly, early acquisition of sign language may circumvent auditory difficulties by providing an alternate route to functional communication. Life course models suggest that many factors contribute to an individual's functional hearing capacity, in ways that are currently poorly understood.

\subsubsection{Maintenance of Function}

In the middle years, adults attempt to maintain hearing function in the face of new risk factors such as occupational noise exposure, alcohol, smoking, etc. Many adults make conscious or subconscious adaptations to maintain function in the face of clinical or subclinical hearing thresh- old drops (e.g., avoiding noisy environments, sitting at the front of lecture halls, turning up the TV volume). The impact of early-life factors on hearing ability in the middle years has not been well studied, and the potential biochemical or cellular mechanisms whereby some individuals may be able to "buffer" a failing auditory pathway while others cannot are unclear.

\subsubsection{Managing Decline}

In old age the emphasis is on functional adaptation to decline in hearing ability. In addition to cogent biochemical and cellular mechanisms underlying the response to falling auditory capacity, social and cultural factors play a large role in acceptance of and accommodations for reduced hearing ability.

To date, there have been no studies documenting hearing ability from birth through to death either at individual or population level, so hearing trajectories can only be estimated using data from separate studies over different phases of the life course (see Fig. 1). We know surprisingly little about how slowly or rapidly hearing ability deteriorates both at individual and population level at different age ranges. We do not know to what degree recognized risk factors for hearing loss in the prenatal and early childhood periods continue to act as risk factors for hearing loss in later childhood, adolescence, and throughout adult life. What is more, there is evidence from animal studies to suggest that an early history of noise exposure can impact auditory function later in life (Fernandez et al. 2015). However, there is little longitudinal data to help determine whether hearing loss in middle and old age is preceded by threshold shifts earlier in life nor whether deteriorations in hearing ability in this middle phase of life occur continuously, or in a stepwise fashion.

Studies that approach hearing loss from a life course perspective are starting to emerge. Wisconsin teenagers actively involved in farm work have been demonstrated to have a higher prevalence of hearing loss compared with their peers who were not engaged in farm work, suggesting that the hearing loss observed in adult farmers may, in fact, begin in childhood and adolescence (Broste et al. 1989). A recent study of over 2000 adults from Tennessee and Pennsylvania 
aged 73-84 years revealed a prevalence of hearing loss ( $>25 \mathrm{dBHL})$ of $59 \%$ at low frequencies and $76.9 \%$ at high frequencies. In a multivariate model, older age, white race, diabetes mellitus, cerebrovascular disease, smoking, poorer cognitive status, occupational noise exposure, and ear surgery were all associated with hearing loss. Possible protective factors included salicylate use (black men) and moderate alcohol intake (black women). National Health Interview Survey analyses have indicated that lower educational levels (less than high school) and lower family income are also associated with higher prevalences of hearing loss (Gates and Mills 2005). Recent animal study data suggest that pathological changes caused by early noise exposure in young mice might actually render inner ears more vulnerable to aging (Kujawa and Liberman 2006), while a retrospective clinical study suggested that noiseinduced hearing loss before old age may reduce the effects of aging at noise-associated frequencies but accelerate deterioration at adjacent frequencies (Gates et al. 2000).

Analysis of short-term longitudinal data from the UK and Denmark reveals that in adult life, hearing ability gradually and continuously deteriorates, at an average rate of $3 \mathrm{~dB}$ per decade for those under 55 and $9 \mathrm{~dB} /$ decade for those over 55 (Davis et al. 1990). A recent short-term US longitudinal study found a similar hearing threshold increase of $1 \mathrm{~dB}$ per year for adults age 60 years and over (Lee et al. 2005). Most US studies report a higher prevalence of hearing loss for men than women across all age ranges; however, more recent studies suggest gender differences might be starting to diminish because of changes in lifestyle (Homans et al. 2016). More boys than girls are born each year with congenital hearing loss, and this increased vulnerability of males to hearing loss continues through the life course. Increased genetic susceptibility and higher rates of exposure to noise, especially occupational exposures, have been proposed as potential causes for the observed gender differences, while estrogen has been hypothesized as exerting potential protective effects against hearing loss for premenopausal women (Hultcrantz et al. 2006). For females in the rural Midwest study, there was a rapid increase in prevalence of hear- ing loss sufficient to interfere with the understanding of speech in the sixth decade, whereas for males it was earlier-in the fourth decade (Flamme et al. 2005), possibly reflecting different environmental exposures, genetic susceptibilities, or both. The Baltimore Longitudinal Study of Aging also showed that hearing sensitivity declines twice as fast in men as in women at most ages and frequencies, with age of onset of decline being later in women. Although women have more sensitive hearing than men at frequencies above $1000 \mathrm{~Hz}$, men have more sensitive hearing than women at lower frequencies (Pearson et al. 1995), an interesting finding which has been replicated in other studies.

Although some studies appear to show a rising prevalence of hearing loss in the USA over time, even after adjusting for age (Wallhagen et al. 1997, Benson and Marano 1994), this has not been confirmed in others (Lee et al. 2004). There is general agreement, however, that with the aging of the "baby boomers," the absolute numbers of individuals who are deaf or hard of hearing in the USA are set to rise. While prevention of hearing loss in old age remains an important goal, life course models emphasize that there are multiple routes to managing such hearing losses, although they require adaptations both at individual population levels. Evidence suggests that powerful social and cultural factors may be limiting these adaptations. For example, less than $15 \%$ for those who would benefit from aids series and only 55\% for those with more severe losses (Popelka et al. 1988) accepted aiding despite good evidence from randomized trials that hearing aids improve outcomes (Yueh et al. 2003). High rates of nondisclosure of hearing loss by students to institutions of higher education (Richardson et al. 2004) and in the workplace have also been reported, suggesting that there may be a stigma attached to disclosure of hearing loss.

\subsection{Social Relationships}

Hearing ability is closely related to ability to communicate via the spoken word and as such has the capacity to impact multiple social relationships. Most children with hearing loss are born to hear- 
ing parents who have no experience of living with and adapting to hearing difficulties. Parents face early decisions regarding whether or not to pursue use of hearing aids and choice of language modality. Historically, intervention programs were divided into signing or oral/aural approaches. Parents faced the difficult decision of choosing one or other route. In more recent years, programs have emerged that address multiple communication modalities, and it is not unusual for children and families to trial several approaches before deciding on a principal course of action. Nonetheless, parents face the sometimes daunting task of acquiring a new language, sign language, in midlife to aid communication with their child. Not surprisingly, studies of language development among children that are deaf or hard of hearing have identified family engagement and maternal sensitivity as important factors influencing outcomes from interventions and maternal sensitivity (Pressman et al. 1999). These findings are very much in tune with life course models that emphasize the importance of social relationships at every stage of health development. Early decisions have a potential for lifelong impact. For example, there may be less-immediate imperative for fathers to become fluent in sign language if mother is the primary caregiver, but in the longterm this is essential for the development of one of the child's pivotal social relationships if sign language is a chosen mode of communication. Parents' abilities to access resources to support communication and relationship building with their child are dependent on factors at multiple levels including financial resources, services offered in their geographic location, parents' ability to take necessary leave from work or limit work hours, support of the wider family including grandparents, aunts, and uncles, and willingness of the local community to make adaptations (e.g., close-captioned TV and interpreter services).

\subsection{Sensitive Periods and Turning Points}

The LCHD model posits that individuals are most susceptible to the effects of multiple risk and protective factors during critical and sensi- tive time periods in development. Many of these sensitive periods occur before birth and in the first years of life, when physiological systems are being initialized and programmed. Health, or lack of health, results from both genetic makeup and both the timing and sequence of biological, psychological, cultural, and historic events.

For example, cytomegalovirus (CMV) infection in the first or second trimester may result in widespread organ damage affecting cognitive and neurological function in addition to hearing loss, while infection later in pregnancy may result only in a progressive hearing loss which develops later in childhood (Rivers et al. 2002), when CMV may not be identified as causative (Pass 2005). Prelingual deafness, occurring prior to the development of language, has far more profound impact than postlingual deafness.

There is considerable debate, however, about the nature of critical and sensitive time periods for early language development. The balance of evidence currently supports early identification of and intervention for hearing loss prior to the sixth month of life as being advantageous for future language development. Consequently, identification of hearing loss no later than age 3 months and commencement of intervention no later than 6 months are important goals of the National Newborn Hearing Screening program; however, some experts suggest that optimal diagnosis and intervention should begin even earlier.

Parents of children with profound losses face another decision with long-term implications when they determine whether they wish their child to receive cochlear implantation. There is some evidence to suggest that early implantation, before the second year of life, results in an advantage of language acquisition over later implantation and that bilateral implantation is advantageous to unilateral. Balanced against this is the desire by some providers and parents to leave one ear free for potential future technologically advanced adaptations and the difficulties inherent in making a decision for the child before they are old enough to express their own view. These difficulties are compounded when the evidence base on which families make these decisions is uncertain at best. Life course models emphasize the importance of professional working in partnership with families, 
providing unbiased information and ensuring they are fully informed about the state of evidence.

Critical timing decisions are not confined to the early years. Young adults with hearing loss often find their need for aiding and hearing supports increase as they progress through the educational system and on to higher education. Older adults entering more acoustically challenging work environments may also need additional supports for the first time. Failure to identify and address these needs could result in unnecessary withdrawal from education or employment.

\subsection{A Developmental Perspective on Hearing Health}

The LCHD model regards health as a "capacity for life," envisaging a continuous dynamic process during which each individual interacts with her environment in ways that either support or inhibit the development of health. Accordingly, a diagnosis of profound hearing loss does not necessarily commit that person to a state of "poor health." Rather, with appropriate adaptations, high levels of communication and interpersonal relationships can be achieved. In fact, many members of the deaf community feel strongly that their condition is not a deficit, do not choose to use assistive technology, and view their choices as quite simply an alternate way of living.

Hearing loss poses particular challenges early in life, especially if it goes undetected. Deprived of auditory input and lacking alternatives such as sign language, infants are challenged to develop a structure or "scaffolding" for language. Evidence suggests that this can affect many other aspects of development including social pragmatics. The impact of hearing loss is closely related to the developmental stage in which it occurs, being strongest when onset is in the prelingual years. Even moderate losses with onset at adolescence can impact social development and academic attainment. Life course models stress the importance of viewing hearing loss in developmental context and ensuring that interventions are developmentally appropriate. In recent years early intervention has shifted from models in which interventionists worked primarily 1:1 with children to one in which the therapist works with the family to support their interactions and interventions with their own child, mirroring the primacy of parent-child interactions at this developmental stage.

A health development perspective emphasizes the importance of considering the individual's developmental stage when tailoring interventions and promoting hearing health. For example, in infancy the emphasis must be on facilitating early communication and primary relationship development; in the preschool and early school years, it will be on communication for wider relationship development and hearing for early learning; in adolescence issues of identity and peer acceptance come to the fore; in adulthood adaptation to the workplace, projection of a competent professional image, romantic relationships, and finding a life partner are prime concerns, followed by becoming a good parent. In old age the focus is on avoidance of being a burden to family and society and maintaining close relationships and quality of life. Each stage requires a related yet focused response from public and individual health services.

\section{$3 \quad$ Implications of Early Hearing Loss for Health Development over the Life Course}

We have already described how early hearing loss sufficient to interfere with speech and language development can negatively impact communication and social skills and education and occupational attainment. However, even mild degrees of loss have been associated with educational challenges including greater likelihood of grade repetition and attention difficulties in school (Bess 1998), while slight bilateral hearing loss, frequently unrecognized by parents, has been associated with lower reading scores (Byrd 2002). Recent studies suggest that many factors impact the expressive vocabularies of children with congenital hearing loss in the first 2 years of life, but that diagnosis and commencement of early intervention prior to the age of 3 months 
has a sustained beneficial effect (Vohr et al. 2011). Children diagnosed early, without significant comorbidities and who receive a cochlear implant up to $45 \%$, are reported to have normal to slightly delayed language development (Verhaert et al. 2008). While cochlear implantation is not the only route to language development, and many factors in addition to age at intervention contribute to language abilities, this finding underscores the importance of the child's experience very early in the life course for future language development.

The quality of studies that investigate developmental effects of early hearing loss varies considerably. Some are confined to those children that have hearing loss as their only condition and have an IQ within the normal range, while others do not exclude children with either additional or related conditions. Consequently, caution must be exercised in ascribing developmental effects solely to the impact of hearing loss. In addition, there are special difficulties inherent in estimating the IQ of children that are deaf or hard of hearing (Vernon 2005), including capacity for testing in the child's language (e.g., sign language). Nonetheless, there is good evidence that children who are hard of hearing find it much more difficult than children with normal hearing to learn vocabulary, grammar, word order, idiomatic expressions, and other aspects of verbal communication (Mohr et al. 2000).

Communication difficulties that persist into adolescence and adult life affect later education, employment, and well-being, and pose significant challenge for day-to-day life (NIDCD Plain Language Strategic Plan 2003). High levels of intelligence do not necessarily protect against significant life challenges. In one study of 57 intellectually gifted deaf and hard of hearing subjects followed longitudinally, almost half graduated from a four-year college, but 39\% experienced mental illness of sufficient severity to warrant inpatient hospitalization or outpatient therapy, and a surprising 30\% were unemployed (Vernon and LaFalce-Launders 1993). Similar (31\%) unemployment rates were found in a group of young Danish adults, aged 20-35 years, with congenital hearing loss versus $12 \%$ in the age- matched hearing population (Parving and Christensen 1993). Disappointingly, a recent Australian study using historic data on the employment of deaf school leavers demonstrated that deaf adults continue to have poor employment outcomes despite access to higher education and legislation prohibiting discrimination. The authors suggested that programs addressing community attitudes to deafness might be needed to bring about change (Winn 2007). This conclusion is consistent with a life course approach to understanding outcomes, as it emphasizes the importance of considering multiple levels of contributory factors, including community attitudes, when investigating well-being at all stages of life. In contrast, a more recent study from the USA of 46 young adults that attended a nonpublic agency school for the deaf reported high levels of college completion and employment (Appelman et al. 2012).

There is mixed evidence regarding the effects of hearing loss on mental health at different stages of the life course. Australian children have been demonstrated to have lower parent-reported psychological well-being than their hearing peers, while those with mild losses actually had poorer health-related quality of life (HRQoL), possibly reflecting added stress resulting from unrealistic expectations of hearing ability (Wake et al. 2004). Dutch youth with auditory disabilities had two to three times higher prevalence of mental health problems than the normative sample in one series (Van Eldik 2005), while elderly prelingually deaf people in Sweden who used sign language showed a greater frequency of depressive symptoms and insomnia than hearing peers, though there was no significant difference in perceived well-being. Interestingly, ageassociated acquired hearing loss has been reported to lead to more emotional issues and social isolation than lifelong hearing loss (Gething 2000), possibly reflecting adjustment and coping issues. In a recent qualitative study, deaf and hard of hearing US adults reported difficulties with access to adequate mental health services, largely due to communication barriers, along with feelings of isolation and stigma (Cabral et al. 2013). In a Lancet review of the 
mental health of deaf people, the authors concluded that early access to effective communication with family members and peers was a protective factor for mental health and that provision of specialist services by professional trained to communicate with deaf people and with sign language interpreters could improve access to both mental health and more general health services. Such access is particularly important for the $25 \%$ of deaf individuals reported to have additional disabilities and a high probability of complex mental health needs (Fellinger et al. 2012). Discussing mental health issues through interpreters is not easy-studies also suggest that careful training is needed to reduce possible role conflicts and ensure conceptual equivalence in real-time translating (Sheppard 2011). Professional services must be culturally competent. Deaf adults report feeling that interpreters were not welcome during mental health encounters and were generally not asked about depressive symptoms even when manifesting signs of depression (Sheppard and Badger 2010).

Deaf and hard of hearing people also report difficulties with access to general health services, and are frequently excluded from health research. Recent community-based participatory research has identified some glaring health inequalities in the deaf community, notably obesity, partner violence, and suicide (Barnett et al. 2012), while other studies have demonstrated inconsistent knowledge of common health issues such as cardiovascular health related to difficulties with communication during health education (McKee et al. 2011). Fewer than one in ten deaf women report fully understanding what the doctor tells them when visiting the doctor's office alone (Ubido 2002).

The relationship between congenital hearing loss and mortality is uncertain. One study showed no excess of mortality among prelingually deaf people compared with hearing controls, although a small excess in mortality was observed for postlingually deafened individuals (Barnett and Franks 1999), again possibly reflecting adjustment and coping difficulties. In the USA, Schubert et al. (2017) studied the associations between hearing, visual, and olfactory impairments with mortality and somewhat surprisingly found that olfactory impairment, but not hearing or visual impairment, was associated with an increased risk of mortality. In Iceland, older men with hearing impairment or dual sensory impairment (vision + hearing loss) had a greater risk of dying from any cause and particularly cardiovascular causes within a median 5-year follow-up. Women with hearing impairment, however, had a nonsignificantly elevated risk (Fisher et al. 2014).

\section{$4 \quad$ Achieving Hearing Health}

Health is increasingly conceptualized not just as the absence of disease but as a positive capacity for life. Achieving "hearing health," then, means more than just avoiding "poor" outcomes. At each stage of life, hearing capacity needs to be sufficient for the functional needs of the individual and for successful interaction with the broader environment. Interventions are no longer aimed at simply remediating deficits but must be tailored to ensure that each individual can meet her needs, develop her full potential, and, regardless of adaptations adopted or chosen method of communication, interact successfully socially with the broader population (Lin et al. 2016). In early childhood, during the period of language acquisition, children with severe and profound hearing loss face significant communication challenges. Early diagnosis, prompt intervention, and ready access to the family's choice of communication modality appear to offer the best hope for successful outcomes. Throughout childhood, optimum hearing capacity needs to be maintained through continuous use of high-quality assistive listening devices such as hearing aids and use of frequency modulation (FM) classroom systems. Access to teachers of the deaf and to sign language and sign language interpreters needs to be provided if children are to meet increasing school curricular demands.

As children who are deaf or hard of hearing transition into higher education or the workforce, they need to have the same range of occupational choices as their hearing peers. The acoustic demands of the workplace may be more challenging than structured classroom settings, presenting 
difficulties even for those with mild or minimal hearing loss. For older adults with age-related or noise-induced hearing loss, the ability to maintain social and occupational functioning is an important goal of habilitation, as even mild degrees of hearing loss may result in difficulties with conversational speech under adverse listening conditions such as the presence of background noise or reverberation (Gordon-Salant 2005). Understanding of accented speech is particularly challenging for the elderly, so the changing demographics of the USA with increasing diversity of accents may pose added challenges in future years. Adoption of a positive functional framework for hearing health implies that assessments of hearing ability at all ages should not be limited to documentation of hearing thresholds under testing conditions but need to measure the individual's functional hearing capacity in their everyday life - an area where even mild limitations may have negative consequences before significant threshold shifts are observed. Similarly, amplification to a specified threshold level may not be sufficient in and of itself to ensure an individual's ability to maintain a prior job function, or to manage social situations in a way that achieves true hearing health.

Hearing health may be achieved in different ways by different individuals - a person with a profound hearing loss who is fluent in sign language and able to communicate successfully with both deaf and hearing peers through the use of readily available translators has found one route to hearing health. For others, it may come with the use of hearing aids. Conversely, the middleaged construction worker who develops a noticeable hearing loss, is unable to afford a hearing aid, and reluctantly avoids social situations due to his communication difficulties is not achieving hearing health. Optimization of hearing healthboth at individual and population levels-could yield significant benefits in quality of communication and social interactions.

Current evidence suggests that many Americans, across all stages of life, are not achieving full hearing health. Until recently, late diagnosis of congenital hearing loss was the norm, with a reported mean age at diagnosis of
24-30 months in 1989 (Gustason 1989; Moore et al. 1990). Consequently, many children (who are now in adulthood) missed the opportunity for very early intervention during a critical and sensitive time period for language acquisition.

Although Universal Newborn Hearing Screening programs have made great strides in reducing ages at diagnosis and intervention, some children still "fall through the cracks," or fail to return for follow-up appointments, and are diagnosed late. The Centers for Disease Control (CDC) Early Hearing Detection and Intervention (EHDI) program aims to promote communication from birth for all children and to ensure that children with hearing loss achieve communication and social skills commensurate with their cognitive ability (National EHDI Goals). Screening of all newborns by 1 month of age, diagnostic evaluations for all screen "refers" by 3 months of age, and commencement of early intervention by 6 months of age are core EHDI goals. However, a 2004 (UPDATE) survey of screening program administrators revealed that only $55 \%$ of infants needing diagnostic audiologic evaluations are receiving them by 3 months of age, and only $48 \%$ of infants confirmed with hearing loss commence early intervention services by age 6 months (Van Naarden and Decoufle 1999). Similar experience has been reported in the UK in a follow-up to the Wessex study, where fitting of aids and commencement of early intervention did not occur in approximately half of cases until the child was over 18 months old (Kennedy et al. 2005). Factors cited by EHDI administrators as contributing to follow-up challenges include shortages of pediatric audiologists, delays in obtaining necessary insurance authorizations, and lack of knowledge of the EHDI system by primary care physicians. Parents too may be reluctant to accept the results of a computerized test of hearing in a baby who appears normal, while cultural biases and negative perceptions of deaf people might contribute to lack of acceptance of diagnosis and lack of compliance with the use of hearing aids (Mutton and Peacock 2005).

While the vast majority of children with moderate or greater degrees of hearing loss will be 
detected by current newborn screening protocols, many cases of milder loss, both bilateral and unilateral, will be missed. When screen protocols reliant only on otoacoustic emissions (OAEs) are used, cases of auditory neuropathy will also be missed. The question of how much benefit results from early detection of mild and unilateral losses remains unanswered, but there is evidence that even mild losses may be associated with academic difficulties, while in one series unilateral losses were demonstrated to be associated with scholastic or behavioral problems in school in up to $30 \%$ affected children (Brookhouser et al. 1991). These findings raise the question of whether earlier intervention for these types of loss might also improve long-term outcomes. Ongoing audiological surveillance throughout childhood is needed if children with late-onset, progressive, or acquired hearing loss are to be identified at the earliest possible time (National EHDI Goals). Although hearing assessment is recommended at each preventive health visit in childhood, the method of the assessment, pass/ fail criteria, and follow-up protocols have not been clearly delineated. Joint Committee on Infant Hearing recommends that any infant with risk indicators for progressive or delayed-onset hearing loss receive audiological monitoring every 6 months until age 3 years, yet risks will probably persist beyond this age. Of children ages 3-19 years, $10 \%$ are reported to "refer" on audiometric screening at pediatrician visits, of whom less than half report receiving any followup services (Halloran et al. 2005), limiting the effectiveness of these screening efforts. Although school-entry hearing screening and intermittent screening throughout the school years are performed through most school districts, there are few published data on the outcomes of these screening programs. For adults, screening is recommended every decade after age 18 years with more frequent monitoring after age 50 or if there are risk factors such as occupational noise exposure. In practice, however, compliance with screening recommendations is low. Acceptance rates of hearing aids in adults are also low-less than $15 \%$ for those who would benefit in one series and only $55 \%$ for those with more severe losses (Popelka et al. 1998)—despite good evidence from high rates of nondisclosure of hearing loss by students to institutions of higher education (Richardson et al. 2004) and in the workplace have also been reported, suggesting that there may be a stigma attached to disclosure of hearing loss.

These findings all suggest that powerful social and cultural factors may act throughout the life course as strong disincentives for the identification and treatment of hearing loss. Indeed, data suggest that the identification of hearing losses later in life is far less complete than in the early years at population level. Hearing aids do not appear to be as well accepted by the population as, for example, glasses - this may reflect issues of cost, availability, and ease of use, but may also reflect negative cultural attitudes. Many health plans, for example, do not cover the provision of hearing aids despite the fact that hearing loss is the third most prevalent chronic condition in older adults (Yueh et al. 2003). In the USA, where hearing aids can cost approximately $\$ 5000$ US dollars, efforts are being made to make hearing technology more affordable and more accessible. In their report, the National Academies of Sciences, Engineering, and Medicine and their task force recommended key institutional, technological, and regulatory changes that would enable consumers to find and fully use appropriate, affordable, and high-quality services and technologies (National Academies 2016). One such recommendation is to implement a new Food and Drug Administration (FDA) device category for over-the-counter wearable hearing devices. Another is to improve affordability of hearing health care by actions across federal, state, and private sectors.

\section{$5 \quad$ Research Priorities}

The Life Course Health Development (LCHD) model provides a comprehensive conceptual framework for understanding both how hearing loss develops and how hearing health can be achieved throughout the life span. This framework can be used to guide formation of a research 
agenda incorporating study of early developmental influences and genetic, environmental, social, societal, and cultural contributors to hearing health. Here we consider priorities for this agenda arising from this application of the model to hearing health. These include the need for a comprehensive knowledge synthesis, adoption of longitudinal interdisciplinary study designs, place of hearing loss registries, better measures of positive hearing health, further development of investigation of pathophysiology of hearing loss, involvement of the deaf and hard of hearing communities in the design and conduct of the research agenda, and more translational research in how best to move evidence into practice.

\subsection{Knowledge Synthesis}

Existing knowledge of auditory pathology resides in multiple disciplinary silos, with few attempts to draw all of the knowledge together into one area. Epidemiologists do not generally read cell biology journals, while psychologists and teachers of the deaf seldom read publications on epigenetics. Yet, each may have knowledge that could prove useful if not invaluable to the other. The LCHD model indicates how diverse factors, being studied by quite separate groups of individuals, contribute to a cohesive whole, with the relationships between factors too often ignored in research studies. The challenge is to gather relevant materials together in such a way that it is comprehensible and readily accessible across disciplines. This paper represents one attempt to move across multiple disciplinary lines and consider, using the life course framework, the myriad of potential factors operating at multiple levels to contribute to hearing ability at individual and population levels.

\subsection{Study Design}

The preceding discussion of a life course view of hearing health makes a strong argument for a need to shift from cross-sectional to longitudinal study designs, and from a uni- or limited disciplinary approach to one in which multiple disciplines contribute to the same study. An "ideal" study would involve following a large cohort prospectively, preferably starting prior to conception and continuing throughout the life span. The study would incorporate detailed measures of hearing health at multiple points during the life course, together with a wide range of additional genetic, epigenetic, biological, general health, environmental, psychological, social, and educational measures. No existing studies fulfill all aspects of the ideal, but a few longitudinal studies do exist that embody some of these features. For example, the National Child Development Study (NCDS; UK) (1958), the British Birth Cohort Study (1970), and the Avon Longitudinal Study of Parents and Children (ALSPAC) each includes some measures of hearing ability. However, even large cohort studies will include only 100-200 children with congenital hearing loss, and the amount of additional data of most interest to hearing researchers will be limited by the length of the study protocol that subjects can reasonably be expected to complete. Large de novo longitudinal studies that are focused on addressing hearingrelated hypotheses will likely be costly and take, potentially, decades to deliver results. The challenge is to develop new approaches that will allow for the study of hearing from a life course perspective in a less costly fashion. Approaches could include addition of follow-forward or follow-back components to existing cross-sectional studies such as National Health and Nutrition Examination Survey (NHANES), which already includes detailed measures of subjects hearing ability; addition of hearing-related data to existing longitudinal studies such as NCDS (UK), Biorepository and Bioanalysis Centre (BBC), ALSPAC, National Longitudinal Survey of Children and Youth (NLSCY), and the National Children's Study (NCS); addition of hearingrelated biological data from selected subjects in cross-sectional studies such as NSCH; and voluntary collection of historical and biological data using approaches such as a hearing loss registry (see below). Any of these approaches would require dedicated funding streams, as they would fall outside of the traditional scope of R01s. 


\subsection{Hearing Loss Registries}

Researchers have traditionally been reluctant to develop disease-specific registries owing to legitimate concerns about confidentiality and a reluctance to ask potential subjects to participate, especially at sensitive times such as shortly after diagnosis. Recently, however, highly successful registries for conditions such as autism have been developed on a voluntary basis, incorporating both detailed patient/family reported data and biological specimens for genetic and biochemical analysis. In addition to subjects with hearing loss, hearing subjects could contribute vital control data. While a voluntary approach undoubtedly introduces bias, the reality is that any existing approach to population study involves some forms of bias both known and unknown. Provided that biases can be documented, there is now potential to address them statistically. Similarly, missing data can be inferred using techniques such as multiple imputations. Experience with other registries suggests that a community-based participatory research approach involving members of the deaf and hard of hearing community working alongside professionals to develop and implement the registry and determine the ways in which data can be accessed is most likely to be successful. Subjects could determine whether they wished to contribute data alone, biological specimens alone, or both, and whether they wished to interface with the registry at a single time point or would be willing to return at intervals. Much of the data collection could be performed online at times convenient for the registry participants. Participants would be free to withdraw at any time. Depending on content, parts of the registry could potentially be made publicly available for analysis provided individual subjects could not be recognized from released data. Most likely, some parts of the dataset would be made available only to researchers who agreed to comply with confidentiality restrictions. Funding for such a registry could be from private or public sources or both. A US-based registry could either interface with similar registries in other countries that were independently run, or an international initiative could be launched aimed at uniformity of approach and data collection in multiple countries, greatly increasing the number of available subjects and potentially accelerating research.

This type of data collection effort also falls outside of traditional research-funding mechanisms and shifts the focus from hypothesis-driven research to one of "big data" collection, where the emphasis is on examining large amounts of data looking for new types of patterns and relationships. While there are legitimate concerns that this type of "data trawling" could lead to "false positives" with recognition of associations occurring by chance, many researchers now argue that this concern could be at least partially overcome by employing more stringent criteria for significance testing, e.g., employing $p$ values of $<0.005$ rather than 0.05 . While some researchers fear a move away from hypothesis-testing, many others now view it as the way forward. In fact there are fears that continuing with strict hypothesis-driven approaches will delay useful research potentially by decades and involve vast amounts of unnecessary expense. Resolving these tensions will be key to establishing a functioning registry.

\subsection{Measures of Positive Hearing Health}

The LCHD model emphasizes that the goal of health development should be to optimize hearing health, not just avoid disease. Life course models view hearing health as a capacity for life, so optimal health incorporates hearing ability that is sufficient for each hearing function that person requires in their daily life, not just reaching a defined threshold on a single hearing test. This might include hearing well even in a noisy work environment, or being able to converse with friends without missing some words in the conversation. Existing audiometrics appear insufficiently sensitive to identify early functional hearing challenges. Researchers need operational measures of positive hearing health, both for better measurement of treatment outcomes and of functional hearing ability. These measures should be developed and trailed by multidisciplinary teams with representation from deaf, hard of hearing, and hearing consumers across a range of ages. In addition, more sensitive measures of environmental noise exposure are needed. 


\subsection{Investigating the Pathophysiology of Hearing Loss}

Further elucidation of the pathophysiology of hearing loss will require a combination of bench and clinical research across multiple disciplines including genetics, biochemistry, cell biology, physiology, and audiology. Greater synthesis of existing knowledge could link information on known genetic variants associated with hearing loss, with suspected polymorphisms that could be related to hearing loss, and with what is known about abnormalities at metabolic, biochemical, subcellular, and cellular processes in individuals with different types of hearing loss. Epidemiologic data on identified clinical associations with hearing loss should be linked with genetic and biochemical data repositories in ways that facilitate the identification of potentially important relationships. More work is needed on elucidating the mechanisms that underlie observed associations, e.g., low socioeconomic status in childhood and later hearing loss, smoking and adult hearing loss, and noise exposure and hearing loss at all ages.

\subsection{Involvement of Deaf and Hard of Hearing Communities in Research}

Widespread understanding of the importance of involving members of the deaf and hard of hearing communities and their families in research on the etiology, diagnosis, and management of hearing loss is driving new efforts to find effective ways to ensure productive partnerships between consumers and researchers. Funding bodies are beginning to invite members of the deaf and hard of hearing community to contribute to boards that set funding agendas and to invite them to review grant applications and new program proposals. Community-based participatory research (CBPR) models envisage the deaf and hard of hearing as integral members of research teams, often suggesting research questions that they, as a community, would like to see answered and suggesting ways to engage deaf and hard of hearing (DHH) subjects in the research. These efforts must be inclusive. Where distinct groups of DHH communities exist, each must be invited to participate fully, even if there will be more than one view on priorities and conduct of research. Input from each of these groups is more likely to lead to a study protocol that will be embraced by a majority of DHH subjects, reducing inherent biases. This work is not easy and would benefit from use of professional facilitators. Metrics must be developed to monitor progress toward true, rather than token, involvement, e.g., reporting of number of DHH individuals on research boards, invited to key meetings, contributing to possible research questions. Life course theory acknowledges the multiple contributors to health at social and community levels, suggesting that there may be much to learn from DHH individuals who have successfully overcome communication, educational, and occupational challenges.

\subsection{Translational Research}

The translation of evidence into practice does not occur automatically and itself requires study. As evidence accrues for the mechanisms underlying hearing health trajectories, investigators will need to test their potential mutability and consider implications for clinical practice. Promising interventions, whether they be pharmacological, surgical, or social, then need to undergo clinical trials (T1) and trials in community-based programs (T2) and then be trialed as new systems of care (T3). Finally, researchers need to test ways to scale and spread successful interventions (T4) before incorporating them into state and national $\mathrm{MCH}$ programs and policies. While funding for T1 research can be obtained through traditional National Institute on Deafness and Other Communication Disorders (NIDCD) R01 mechanisms, funding of other types of translational research falls at the intersection of NIDCD and other agencies such as Agency for Healthcare Research and Quality (AHRQ). The reality is that funding for this type of research is very limited. In addition, life course models indicate that successful interventions will likely have both "medical" 
and "social" components, potentially making them less likely to be funded through traditional health mechanisms. Public-private partnerships may provide innovative ways to fund this type of research, which may cut across traditional barriers between health and education, or health and occupational development.

\section{$6 \quad$ Implications for Policy and Practice}

\subsection{Impact Studies}

Life course models acknowledge that policies affecting women of childbearing age and young children can have profound direct and indirect effects on the health of the next generation. Infrastructure and funding must be developed for studying the impact of existing and proposed policy changes on hearing health. For example, fiscal challenges have resulted in a number of states offering early intervention services to children with moderate or greater bilateral hearing loss, while children with mild and unilateral losses are deemed ineligible, despite the existence of at least moderately good evidence that these children also face additional challenges with school performance. This type of policy may prove to be a "false economy" if children that missed out on early intervention ultimately, as adults, lack skills that they would have acquired had intervention been available to them. Balancing the evidence may require additional studies, or use of computer simulation models, to make a best estimate of cost-benefits.

\subsection{Integrated Services}

Services for children and adults that are DHH are separated into "medical" interventions including auditory surgery and cochlear implantation, "developmental" interventions such as early intervention, "social" interventions such as family support services, and "mental health" interventions such as counseling. Life course models suggest that in order to achieve optimal hearing health trajectories, these services must be integrated into a cohesive whole, preferably with a single point of entry, rather than operated and run independently with minimal communications between providers. While electronic medical records may help with information flow, the provision of community-based services poised to address all the needs of DHH individuals will require a transformation of the present system of care and a blurring of the boundaries between health, educational, and social services.

\subsection{Public Information Campaign}

The LCHD model acknowledges that cultural and social pressures can have a major impact on health. Many deaf people report feeling marginalized in society, while reluctance to wear hearing aids among some individuals that are hard of hearing stems from a desire to keep their condition hidden. These cultural issues are powerful barriers to the achievement of full hearing health for many. A national and international campaign is needed to inform the general public about the nature of deafness and the importance of respecting deaf culture and communication choices. For people who are hard of hearing and who choose to wear hearing aids, use of hearing aids must be destigmatized. Use of accommodations such as closed captioning and telephone interpreter services should be strongly encouraged even for those that can function, albeit imperfectly, without them. Involvement of the DHH community in the planning and execution of this campaign is essential. The internet and social media including Facebook and Twitter offer ideal venues to distribute information and challenge cultural assumptions.

\subsection{Costs and Cost-Effectiveness}

Hearing loss has profound economic implications for individuals, families, and society as a whole. Comprehensive economic studies are needed to address the true costs of hearing loss at all levels. New policies must incorporate strong 
consideration of cost-effectiveness in preventive and treatment measures across all stages of the life span. The provision of amplification aids to a much wider proportion of the population in a cost-effective manner is a research and policy priority (National Academies 2016).

\section{Conclusions}

The Life Course Health Development model offers a conceptual framework for understanding the many genetic, biological, social, psychological, and cultural factors that contribute to hearing health over a lifetime. Early life events and experiences can have profound effects on hearing trajectories with lifelong consequences. Shifting trajectories involves altering the balance between risk and protective factors, especially during critical and sensitive periods of development including fetal life and the prelingual period in the first 6 months of postnatal life. Early diagnosis and intervention, early exposure to language whether signed or oral, warm reciprocal parent-infant relationships regardless of communication modality, broad family support, responsive school and work environments, and policies that enable lifelong supports can combine to lead to good outcomes. The goal of management is optimal hearing health, not just avoidance of poor auditory function. New measures of positive hearing health are needed to drive research on optimal hearing function.

Universal Newborn Hearing Screening has achieved early diagnosis and intervention for many, but loss to follow-up threatens the success of the program and can have long-reaching consequences in individual cases. People who are deaf and/or hard of hearing face continuing challenges with educational achievement and workplace function. Addressing hearing loss later in life will require multiple approaches including a greater focus on early prevention, reduction to noise exposure throughout the life span, reductions in smoking and excessive alcohol consumption, and avoidance of excessive weight gain. The focus of research must shift from uni- and bi-disciplinary cross-sectional designs to inter- disciplinary longitudinal cohort studies that incorporate both historical and biological data. Voluntary hearing loss registries, both national and international, could provide "big data" for new research approaches to studying the etiology and management of hearing loss. Transdisciplinary knowledge synthesis, potentially adopting a wiki-type framework, could provide a resource for use across disciplines by providers, researchers, and consumers. Research into the pathophysiology of hearing loss must cut across traditional boundaries, embracing genetic, epigenetic, biological, and cellular mechanisms incorporating a health development perspective.

There is considerable wisdom in the deaf and hard of hearing communities that should be utilized both in assisting newly diagnosed DHH individuals in achieving optimal functioning and in driving the research and service improvement agenda. Focused studies must address the impact of existing and proposed policies on hearing health, while management of established hearing loss requires a more integrated approach across health education and social services. Achieving optimal hearing health for all will require cultural and societal shifts in which deafness is destigmatized and an inclusive agenda actively pursued for the deaf and hard of hearing across all stages of the life span. Optimal hearing health in childhood must be prioritized as the foundation for lifelong hearing health in the US population.

\section{References}

Appelman, K. I., Callahan, J. O., Mayer, M. H., Luetke, B. S., \& Stryker, D. S. (2012). Education, employment and independent living of young adults who are deaf and hard of hearing. Am Ann Deaf, 157(3), 264-275.

Appollonio, I., Carabellese, C., Frattola, L., \& Trabucchi, M. (1996). Effects of sensory aids on the quality of life and mortality of elderly people: A multivariate analysis. Age and Ageing, 25(2), 89-96.

Augustsson, I., \& Engstrand. (2005). Hearing loss as a sequel of secretory and acute otitis media as reflected by audiometric screening of Swedish conscripts. International Journal of Pediatric Otorhinolaryngology, 70(4), 703-710.

Baltes, P. B., Lindenberger, U., \& Staudinger, U. M. (2007). Life span theory in developmental psychol- 
ogy. In Handbook of child psychology (Vol. 1, p. 11). Hoboken: John Wiley and Sons. Accessed onlinelibrary.wiley.com.

Barnett, S., \& Franks, P. (1999). Deafness and mortality: Analysis of linked data from the National Health Interview Survey and National Death Index. Public Health Rep, 114(4), 330-336.

Barrenas, M. L., Brathall, A., \& Dahlgren, J. (2005a). The association between short stature and sensorineural hearing loss. Hearing Research, 205(1-2), 123-130.

Barrenas, M. L., Jonsson, B., Tuvemo, T., Hellstrom, P. A., \& Lundgren, M. (2005b). High risk of sensorineural hearing loss in men born small for gestational age with and without obesity or height catch up growth: A prospective longitudinal register study on birth size in 245,000 Swedish conscripts. The Journal of Clinical Endocrinology and Metabolism, 90(8), 4452-4456.

Benson, V., \& Marano, M. A. (1994). Current estimates from the National Health Interview Survey, 1993, vital health stat 3. Tackling inequality: Get them while they're young. British Medical Journal, 340, c346-c348. 190: DHHS Publication PHS 95-1518.

Bhasin, T. K., Brocksen, S., Avchen, R. N., \& Van Naarden Braun, K. (2006). Prevalence of four developmental disabilities among children aged 8 years - Metropolitan Atlanta developmental disabilities surveillance program, 1996 and 2000. MMWR Surveillance Summaries, 55(1), 1-9. Erratum in MMWR Morb Mortal Wkly Rep. (2006) Feb 3, 55(4):105-6.

Bess, F. H., Dodd-Murphy, J., \& Parker, R. A. (1998). Children with minimal sensorineural hearing loss: Prevalence, educational performance, and functional status. Ear Hear, 19(5), 339-354.

Bitner-Glindzicz, M. (2002). Hereditary deafness and phenotyping in humans. British Medical Bulletin, 63, 73-94.

Blanchfield, B. B., Feldman, J. J., Dunbar, J. L., \& Gardner, E. N. (2001). The severely to profoundly hearingimpaired population in the United States: Prevalence estimates and demographics. Journal of the American Academy of Audiology, 12(4), 183-189.

Brookhouser, P. E., Worthington, D. W., \& Kelly, W. J. (1991). Unilateral hearing loss in children. Laryngoscope, 101(12Pt 1), 1264-1272.

Broste, S. K., Hansen, D. A., Strand, R. L., \& Stueland, D. T. (1989). Hearing loss among high school farm students. American Journal of Public Health, 79(5), 619-622.

Cabral, L., Muhr, K., \& Savageau, J. (2013). Perspectives of people who are deaf and hard of hearing on mental health, recovery, and peer support. Community Ment Health J, 49(6), 649-657. Epub 2012 Nov 13.

Christensen, K., Fredericksen, H., \& Hoffman, H. J. (2001). Genetic and environmental influences on self-reported reduced hearing in the old and oldest old. Journal of the American Geriatrics Society, 49(11), 1512-1517.

Chung, J. H., DesRoches, C. M., Meunier, J., \& Eavey, R. D. (2005). Evaluation of noise-induced hearing loss in young people using a web-based survey technique. Pediatrics, 115, 861-867.
Clinard, C. G., \& Tremblay, K. L. (2013). Aging degrades the neural encoding of simple and complex sounds in the human brainstem. Journal of the American Academy of Audiology, 24(7), 590-599. quiz 643-4.

Cohn, E. S., \& Kelley, P. M. (1999). Clinical phenotype and mutations in connexin 26 (DFNB1/GJB2), the most common cause of childhood hearing loss. American Journal of Medical Genetics, 89(3), 130-136.

Cruickshanks, K. J., Wiley, T. L., Tweed, T. S., et al. (1998). Prevalence of hearing loss in older adults in Beaver dam, Wisconsin: The Epidemiology of hearing loss study. American Journal of Epidemiology, 148(9), 879-886.

Danielson, R W. (2005). Hearing loss preventionprevention of hearing loss from noise exposure. Better hearing Institute http://www.betterhearing.org/hearing_loss_prevention. Accessed 12/29/05.

Das, V. K. (1996). Aetiology of bilateral sensorineural hearing impairment in children: A 10 year study. Archives of Disease in Childhood, 74(1), 8-12.

Davis, A., McMahon, C. M., Pichora-Fuller, K. M., Russ, S., Lin, F., Olusanya, B. O., Chadha, S., \& Tremblay, K. L. (2016). Aging and hearing health: The lifecourse approach. The Gerontologist, 56(Suppl 2), S256-S267.

Davis, A. C. (1989). The prevalence of hearing impairment and reported hearing disability among adults in Great Britain. International Journal of Epidemiology, 18, 911-917. Cited in Smith, R J., Bale, J F., White, K R. (2005) Sensorineural hearing loss in children. Lancet, 365, 879-90.

Davis, A. C., Ostri, B., \& Parving, A. (1990). Longitudinal study of hearing. Acta Oto-Laryngologica. Supplementum, 476, 12-22.

DeStefano, A. L., Gates, G. A., Heard-Costa, N., \& Myers, R. H. (2003). Baldwin CT. Archives of Otolaryngology - Head \& Neck Surgery, 129(3), 285-289.

Fernandez, K. A., Jeffers, P. W., Lall, K., Liberman, M. C., \& Kujawa, S. G. (2015). Aging after noise exposure: Acceleration of cochlear synaptopathy in "recovered" ears. The Journal of Neuroscience, 35(19), 7509-7520.

Finitzo, T., Albright, K., \& O'Neal, J. (1998). The newborn with hearing loss: Detection in the nursery. Pediatrics, 102(6), 1452-1460.

Fischel-Ghodsian, N. (2003). Mitochondrial deafness. Ear and Hearing, 24(4), 303-313.

Fisher, D., Li, C. M., Chiu, M. S., Themann, C. L., Petersen, H., Jónasson, F., Jónsson, P. V., Sverrisdottir, J. E., Garcia, M., Harris, T. B., Launer, L. J., Eiriksdottir, G., Gudnason, V., Hoffman, H. J., \& Cotch, M. F. (2014). Impairments in hearing and vision impact on mortality in older people: The AGES-Reykjavik study. Age and Ageing, 43(1), 69-76.

Flamme, G. A., Mudipalli, V. R., Reynolds, S. J., Kelly, K. M., Stromquist, A. M., Zwerling, C., Burmeister, L. F., Peng, S. C., \& Merchant, J. A. (2005). Prevalence of hearing impairment in a rural midwestern cohort : 
Estimates from the Keokuk county rural health study, 1994 to 1998. Ear and Hearing, 26(3), 350-360.

Fligor, B. J., Neault, M. W., Mullen, C. H., Feldman, H. A., \& Jones, D. T. (2005). Factors associated with sensorineural hearing loss among survivors of extracorporeal membrane oxygenation therapy. Pediatrics, 115(6), 1519-1528.

Fellinger, J., Holtzinger, D., \& Pollard, R. (2012). Mental health of deaf people. Lancet, 379(9820), 1037-1044.

Fortnum, H. M., Summerfield, A. Q., Marshall, D. H., Davis, A. C., \& Bamford, J. M. (2001). Prevalence of permanent childhood hearing impairment in the United Kingdom and implications for universal neonatal hearing screening: Questionnaire based ascertainment study. British Medical Journal, 323(7312), 536-540.

Gates, G. A., \& Mills, J. H. (2005). Presbycusis. Lancet, 366(9491), 1111-1120.

Gates, G. A., Cooper, J. C. J. R., Kannel, W. B., et al. (1990). Hearing in the elderly: The Framingham cohort, 1983-1985. Part 1. Basic audiometric test results. Ear and Hearing, 11(4), 247-256.

Gates, G. A., Schmid, P., Kujawa, S. G., Nam, B., \& D'Agostino, R. (2000). Longitudinal threshold changes in older men with audiometric notches. Hearing Research, 141(1-2), 220-228.

Gething, L. (2000). Ageing with long-standing hearing impairment and deafness. International Journal of Rehabilitation Research, 23(3), 209-215.

Gordon-Salant. (2005). Hearing loss and aging: New research findings and clinical implications. Journal of Rehabilitation Research and Development, 42(4), 9-24.

Gurtler, N., Schmuziger, N., Kim, Y., Mhatre, A. N., Jungi, M., \& Lalwani, A. K. (2005). Audiologic testing and molecular analysis of $12 \mathrm{~S}$ rRNA in patients receiving aminoglycosides. The Laryngoscope, 115(4), 640-644.

Gustason, G. (1989). Early identification of hearing impairment in infants: A review of Israeli and American progress. Volta Review, 91, 291-295.

Halfon, N., \& Forrest, C. B. (2017). The emerging theoretical framework of life course health development. In N. Halfon, C. B. Forrest, R. M. Lerner, \& E. Faustman (Eds.), Handbook of life course health-development science. Cham: Springer.

Helzner, E. P., Cauley, J. A., Pratt, S. R., Wisniewski, S. R., Zmuda, J. M., Talbott, E. O., de Rekeneire, N., Harris, T. B., Rubin, S. M., Simonsick, E. M., Tylavsky, F. A., \& Newman, A. B. (2005). Race and sex differences in age-related hearing loss: The health, aging and body composition study. Journal of the American Geriatrics Society, 53(12), 2119-2127.

Hertzman, C., Siddiqi, A., Hertzman, E., Irwin, L., Vaghri, Z., Houweling, T. A., Bell, R., Tinajero, A., \& Marmo, M. (2010). Tackling inequality: Get them while they're young. British Medical Journal, 340, c346-c348.

Halloran, D. R., Wall, T. C., Evans, H. H., Hardin, J. M., \& Woolley, A. L. (2005). Hearing screening at well-child visits. Arch Pediatr Adolesc Med, 159(10), 949-955.

Holt, JA. (1993) Stanford Achievement Test. 8th Ed: Reading Comprehension Subgroup Results. Am Ann Deaf. 138, 172-5 cited in Durieux-Smith
A. Chapter VII in Early Hearing and Communication Development accessed at http://www.phac-aspc.gc.ca/ publicat/eh-dp/chap7_e.html 11/10/-05.

Homans, N. C., Metselaar, R. M., Dingemanse, J. G., van der Schroeff, M. P., Brocaar, M. P., Wieringa, M. H., Baatenburg de Jong, R. J., Hofman, A., \& Goedegebure, A. (2016). Prevalence of age-related hearing loss, including sex differences, in older adults in a large cohort study. Laryngoscope, 127(3), 725-730.

Hultcrantz, M., Simonoska, R., \& Stenberg, A. E. (2006). Estrogen and hearing: A summary of recent investigations. Acta Oto-Laryngologica, 126(1), 10-14.

Kelley, P. M., Cohn, E., \& Kimberling, W. J. (2000). Connexin 26: Required for normal auditory function. Brain Research. Brain Research Reviews, 32(1), 184-188.

Kennedy, C., McCann, D., Campbell, M., Kimm, L., \& Thornton, R. (2005). Universal newborn screening for permanent childhood hearing impairment: An 8 year follow-up of a controlled trial. Lancet, 366, 660-662.

Kujawa, S. G., \& Liberman, M. C. (2006). Acceleration of age-related hearing loss by early noise exposure: Evidence of a misspent youth. The Journal of Neuroscience, 26(7), 2115-2123.

Kuzawa, C. W., \& Thayer, Z. M. (2011). Timescales of human adaptation: The role of epigenetic processes. Epigenomics, 3(2), 221-234.

Lee, D. J., Gomez-Martin, O., Lam, B. L., \& Zheng, D. D. (2004). Trends in hearing impairment in United States adults: The national health interview survey, 19861995. Journal of Gerentol. A. Biological Medical Science, 59(11), 1186-1190.

Lee, F. S., Matthews, L. J., Dubno, J. R., \& Mills, J. H. (2005). Longitudinal study of pure tone thresholds in older persons. Ear and Hearing, 26(1), 1-11.

Levine, D., Strother-Garcia, K., Golinkoff, R. M., \& Hirsh-Pasek, K. (2016). Language development in the first year of life: What deaf children might be missing before Cochlear implantation. Otology \& Neurotology, 37(2), e56-e62.

Lin, F. R., Hazzard, W. R., \& Blazer, D. G. (2016). Priorities for improving hearing health Care for Adults: A report from the National Academies of Sciences, Engineering, and Medicine. Journal of the American Medical Association, 316(8), 819-820.

Low, F. M., Gluckman, P. D., \& Hanson, M. A. (2011). Developmental plasticity and epigenetic mechanisms underpinning metabolic and cardiovascular diseases. Epigenomics, 3(3), 279-294.

Mason, J. A., \& Herrmann, K. R. (1998). Universal infant hearing screening by automated auditory brainstem response measurement. Pediatrics, 101(2), 221-228.

Marlow, E. S., Hunt, L. P., \& Marlow, N. (2000). Sensorineural hearing loss and prematurity. Archives of Disease in Childhood. Fetal and Neonatal Edition, 82, F141-F144.

Mehl, A. L., \& Thomson, V. (2002). The Colorado newborn hearing screening project, 1992-1999: On the threshold of effective population-based universal newborn hearing screening. Pediatrics, 109(1), E7. 
McKee, M., Schlehofer, D., Cuculick, J., Starr, M., Smith, S., \& Chin, N. P. (2011). Perceptions of cardiovascular health in an underserved community of deaf adults using American Sign Language. Disabil Health J, 4(3), 192-197.

Mitchell, R. E. (2005). How many deaf people are there in the United States: Estimates from the survey of income and program participation. Journal of Deaf Studies and Deaf Education, 11(1), 112-119. [Epub].

Mohr, P. E., Feldman, J. J., Dunbar, J. L., McConkeyRobbins, A., Niparko, J. K., Rittenhouse, R. K., \& Skinner, M. W. (2000). The societal costs of severe to profound hearing loss in the United States. Int $J$ Technol Assess Health Care, 16(4), 1120-1135.

Moore, W. G., Josephson, J. A., \& Mauk, G. W. (1990). Identification of children with hearing impairments: A baseline survey. The Volta Review, 93, 187-196.

Mutton, P., \& Peacock, K. (2005). Neonatal hearing screens: Wessex re-visited. Lancet, 366, 612-613.

Nance, W. E. (2003). The genetics of deafness. Mental Retardation and Developmental Disabilities Research Reviews, 9(2), 109-119.

National Academies of Sciences, Engineering and Medicine (2016). Hearing Health Care for Adults: Priorities for Improving Access and Affordability. http://nationalacademies.org/hmd/reports/2016/ Hearing-Health-Care-for-Adults.aspx.

National Center for Health Statistics, Data from the National Health Interview Survey 1994, Series 10, Number 188. National EHDI Goals http://www.cdc. gov/ncbdd/ehdi/nationalgoals.htm.

National Institute in Deafness and Other Communication Disorders. Noise-induced hearing loss (2002). NIH Pub. NO. 97-4233 Bethesda MD cited in The prevalence and Incidence of hearing Loss in Children http://www.asha.org/public/hearing/disorders/children.htm.

National Institute on Deafness and other Communication Disorders (NIDCD) Strategic Plan: Plain Language Version FY 2003-2005 2017. Accessed July 6th 2017 at https://www. nidcd.nih.gov/about/strategic-plan/2003-2005/ strategic-plan-plain-language-version-fy-2003-2005

Niskar, A. S., Kieszak, S. M., Holmes, A. E., Esteban, E., Rubin, C., \& Brody, D. J. (2001). Estimated prevalence of noiseinduced hearing threshold shifts among children 6 to 19 years of age: The third National Health and Nutrition Examination Survey, 1998-1994, United States. Pediatrics, 108(1), 40-43.

Park, J., Lombardino, L. J., \& Ritter, M. (2013). Phonology matters: A comprehensive investigation of reading and spelling skills of school-age children with mild to moderate sensorineural hearing loss. Am Ann Deaf, 158(1), 20-40.

Parving, A., \& Christensen, B. (1993). Training and employment in hearing-impaired subjects at 20-35 years of age. Scandinavian Audiology, 22(2), 133-139.

Parving, A., \& Christensen, B. (1996). Epidemiology of permanent hearing impairment in children in relation to costs of a hearing health surveil- lance program. International Journal of Pediatric Otorhinolaryngology, 34, 9-23.

Pass, R. F. (2005). Congenital cytomegalovirus infection and hearing loss. Herpes, 12(2), 50-55.

Pearson, J. D., Morrell, C. H., Gordon-Salant, S., Brant, L. J., Metter, E. J., Klein, L. L., \& Fozard, J. L. (1995). Gender differences in a longitudinal study of ageassociated hearing loss. Journal of the Acoustical Society of America, 97(2), 1196-1205.

Popelka, M. M., Cruickshanks, K. J., Wiley, T. L., Tweed, T. S., Klein, B. E., \& Klein, R. (1998). Low prevalence of hearing aid use among older adults with hearing loss: The Epidemiology of hearing loss study. Journal of the American Geriatrics Society, 46(9), 1168-1169.

Pressman, L., Pipp-Siegel, S., Yoshinaga-Itano, C., \& Deas, A. (1999). Maternal sensitivity predicts language gain in preschool children who are deaf and hard of hearing. Journal of Deaf Studies and Deaf Education, 4(\$), 294-304.

Reavis, K. M., Tremblay, K. L., \& Saunders, G. (2016). How can public health approaches and perspectives advance hearing health care? Ear and Hearing, 37(4), 376-380.

Richardson, J. T., Long, G. L., \& Woodley, A. (2004). Students with an undisclosed hearing loss: A challenge for academic access, progress, and success? Journal of Deaf Studies and Deaf Education, 9(4), 427-441.

Rivers, B., Boppana, S. B., Fowler, K. B., Britt, W. J., Stagno, S., \& Pass, R. F. (2002). Predictors of hearing loss in children with symptomatic congenital cytomegalovirus infection. Pediatrics, 110, 762-767.

Rosanowski, F., Eysholdt, U., \& Hoppe, U. (2006). Influence of leisure-time noise on outer hair cell activity in medical students. Int Arch Occup Environ health, 80(1), 25-31.

Russ, S. (2001). Measuring the prevalence of permanent childhood hearing impairment. British Medical Journal, 323(7312), 725-726.

Russ, S. A., Poulakis, Z., Barker, M., Wake, M., Rickards, F., \& Saunders, K. (2003). Oberklaid F Epidemiology of congenital hearing loss in Victoria. Australia International Journal Audiology, 42, 385-390.

Ryding, M., White, P., \& Kalm, O. (2005). Course and long-term outcome of "refractory" secretory otitis media. The Journal of Laryngology and Otology, 119(2), 113-118.

Schubert, C. R., Fischer, M. E., Pinto, A. A., Klein, B. E. K., Klein, R., Tweed, T. S., \& Cruickshanks, K. J. (2017). Sensory impairments and risk of mortality in older adults. The Journals of Gerontology Series A: Biological Sciences and Medical Sciences, 72(5), 710-715.

Sheppard, K., \& Badger, T. (2010). The lived experience of depression among culturally Deaf adults. J Psychiatr Ment Health Nurs, 17(9), 783-789.

Sheppard, K. (2011). Using American sign language interpreters to facilitate research among deaf adults: Lessons learned. J Transcult Nurs, 22(2), 129-134.

Smith, R. J., Bale, J. F., \& White, K. R. (2005). Sensorineural hearing loss in children. Lancet, 365, 879-890. 
Tremblay, K. L., Pinto, A., Fischer, M. E., Klein, B. E., Klein, R., Levy, S., Tweed, T. S., \& Cruickshanks, K. J. (2015). Selfreported hearing difficulties among adults with normal audiograms: The beaver dam offspring study. Ear Hear, 36(6), e290-e299.

Ubido, J., Huntington, J., \& Warburton, D. (2002). Inequalities in access to healthcare faced by women who are deaf. Health Soc Care Community, 10(4), 247-253.

Uchida, Y., Nakshimat, T., Ando, F., Niino, N., \& Shimokata, H. (2005). Is there a relevant effect of noise and smoking on hearing? A population-based aging study. International Journal of Audiology, 44(2), 86-91.

US Department of Health and Human Services Healthy Hearing 2010 Progress Report. (2010). www. healthypeople.gov/data/2010prog/focus28 Accessed 2/21/06

Van Eldik, T. (2005). Mental health problems of Dutch youth with hearing loss as shown on the youth self report. American Annals of the Deaf, 150(1), 11-16.

Van Naarden, K., \& Decoufle, P. (1999). Relative and attributable risks for moderate to profound bilateral sensorineural hearing impairment associated with lower birth weight in children 3 to 10 years old. Pediatrics, 104(4 Pt 1), 905-910.

Van Naarden, K., Decoufle, P., \& Caldwell, K. (1999). Prevalence and characteristics of children with serious hearing impairment in metropolitan Atlanta, 1991-1993. Pediatrics, 103, 570-575.

Verheart, N., Willems, M., Van Kerschaver, E., \& Desloovere, C. (2008). Impact of early hearing screening and treatment on language development and educa- tion level: Evaluation of 6 years of universal newborn hearing screening (ALGO) in Flanders, Belgium. Int $J$ Pediatr Otorhinolaryngol, 72(5), 599-608.

Vernon, M., \& LaFalce-Landers, E. (1993). A longitudinal study of intellectually gifted deaf and hard of hearing people. Educational, psychological and career outcomes. Am Ann Deaf, 138(5), 427-434.

Vernon, M. (2005). Fifty years of research on the intelligence of deaf and hard-of-hearing children: A review of literature and discussion of implications. J Deaf Stud Deaf Educ Summer, 10(3), 225-231.

Vohr, B., Jodoin-Krauzyk, J., Tucker, R., Topol, D., Johnson, M. J., Ahlgren, M., \& Pierre, L. S. (2011). Expressive vocabulary of older children with hearing loss in the first 2 years of life; Impact of early intervention. J Perinatol, 31(4), 274-280.

Wake, M., Hughes, E. K., Collins, C. M., \& Poulakis, Z. (2004). Parent-reported health-related quality of life in children with congenital hearing loss: A population study. Ambulatory Pediatrics, 4(5), 411-417.

Wallhagen, M. I., Strawbridge, W. J., Cohen, R., \& Kaplan, G. A. (1997). An increasing prevalence of hearing impairment and associated risk factors over three decades of the Alameda County study. American Journal Public Heaith, 87(3), 440-442.

Winn, S. (2007). Employment outcomes for people in Australia who are congenitally deaf: Has anything changed? Am Ann Deaf, 152(4), 382-390.

Yueh, B., Shapiro, N., MacLean, C. H., \& Shekelle, P. G. (2003). Screening and management of adult hearing loss in primary care: Scientific review. JAMA, 289(15), 1976-1985.

Open Access This chapter is licensed under the terms of the Creative Commons Attribution 4.0 International License (http://creativecommons.org/licenses/by/4.0/), which permits use, sharing, adaptation, distribution and reproduction in any medium or format, as long as you give appropriate credit to the original author(s) and the source, provide a link to the Creative Commons license and indicate if changes were made.

The images or other third party material in this chapter are included in the chapter's Creative Commons license, unless indicated otherwise in a credit line to the material. If material is not included in the chapter's Creative Commons license and your intended use is not permitted by statutory regulation or exceeds the permitted use, you will need to obtain permission directly from the copyright holder. 